\title{
САМООЦЕНКА И УРОВЕНЬ ПРИТЯЗАНИЙ У ДЕТЕЙ ДОШКОЛЬНОГО ВОЗРАСТА
}

\section{Смирнова Олеся Викторовна}

воспитатель высшей категории

МБДОУ «ДС «Улыбка» п. Ханымей Пуровского района

Аннотация: Вся психическая жизнь ребенка развивается под воздействием оценок окружающих; каждый новый опыт, новое знание, умение, приобретенное ребенком, оценивается окружающими.

В статье представлен опыт работы по данной теме.

Автор излагает, направления, этапы, развития самооценки у детей дошкольного возраста.

А также, разнообразные тесты, с помощью которых можно уточнить представления о самооценке и уровне притязаний ребенка.

Ключевые слова: самооценка, направления самооценки, этапы самооценки, тест «Лесенка», тест «Смешные человечки», тест «Почему не получается», тест «Какой Я», рекомендации по формированию адекватной самооценки детей дошкольного возраста.

\section{SELF-ESTEEM AND THE LEVEL OF CLAIMS IN PRESCHOOL CHILDREN}

\section{Olesya Viktorovna Smirnova}

Abstract: The whole mental life of the child develops under the influence of the assessments of others; each new experience, new knowledge, and skill acquired by the child is evaluated by others.

The article presents the experience of working on this topic.

The author describes the directions, stages, and development of self-esteem in preschool children.

And also, a variety of tests, with the help of which you can clarify the idea of self-esteem and the level of claims of the child.

Key words: self-esteem, direction, self-evaluation, self-assessment steps, test "Ladder" test "Funny men" test "Why not" test "What I am", and recommendations for the formation of an adequate self-esteem of children of preschool age. 
Проблема возникновения и развития самооценки является одной из центральных в развитии личности. Самооценка является необходимым компонентом самосознания, т.е. осознания человеком самого себя, своих физических сил, умственных способностей, поступков, мотивов и целей своего поведения, отношения к окружающему, к другим людям, самому себе.

Самооценка включает в себя умение оценить свои силы и возможности, отнестись к себе критически. Она позволяет человеку примеривать свои силы к задачам и требованиям окружающей среды и в соответствии с этим самостоятельно ставить перед собой определенные цели и задачи.

По отношению к дошкольникам повышение активности и сознательности означает, развитие у них способности реалистически оценивать собственные возможности при достижении определенных целей в различных видах деятельности, а также формирование умения согласовывать свои действия с интересами и потребностями других людей на основе правильной оценки своих личностных качеств, а также - партнеров по общению. Названные особенности психической регуляции ребенкадошкольника являются необходимым условием подготовки его к школьному обучению, которое, как известно, носит коллективный характер.

Известно, что у дошкольника потребность во внешней оценке чрезвычайно велика, но она не всегда в полной мере удовлетворяется. Ребенок, по мнению Л.И. Божович, стремится стать именно таким, каким его видит взрослый. Следовательно, одним из аспектов понимания тенденции развития и возможного прогнозирования динамических изменений в самосознании, в том числе в развитии общей и частной самооценки ребенка, может служить изучение отношения к нему со стороны социальной среды, и в первую очередь со стороны родителей.

В большинстве работ самооценка ребенка-дошкольника рассматривается в структуре его образа "Я", представляющего собой к концу старшего дошкольного возраста относительно устойчивое образование.

Самооценка внешне выражается в том, как человек оценивает возможности и результаты своей деятельности и деятельности других.

Психологические исследования убедительно доказывают, что особенности самооценки влияют и на эмоциональное состояние, и на степень удовлетворенности своей работой, учебой, жизнью, и на отношения с окружающими.

Через самооценку ребенок проходит такие стадии: потребность в саморазвитии, в самопознании, в самоконтроле. 
В дошкольном возрасте самооценка развивается по следующим направлениям:

1) возрастает число качеств личности и видов деятельности, которые оценивает ребенок;

2) самооценка от общей переходит к дифференцированной;

3) оценка себя во времени.

Главным достижением этого возраста является четкая, уверенная, в целом эмоционально положительная самооценка.

В действительности у человека существует несколько сменяющих друг друга образов «Я». Представление индивида о себе в текущий момент, в момент самого переживания обозначается как «Я - реальное». Помимо этого у человека существует представление о том, каким он должен быть, чтобы соответствовать собственным представлениям об идеале, так называемое «Я идеальное».

Особенностью детей дошкольного возраста является полное признание ими авторитета взрослого (в отличие от дошкольного периода на первый план выходит авторитет учителя), они безоговорочно принимают его оценки. Таким образом, в этом возрасте самооценка ребенка напрямую зависит от характера оценок, которые взрослый дает личностным качествам ребенка и его успехам в различных видах деятельности.

В целом развитие самооценки проходит 4 этапа:

1 этап - от рождения до 18 месяцев. Основа формирования позитивного самоощущения, приобретение чувства доверия к окружающему миру, формирования позитивного отношения к самому себе.

2 этап - от 1,5 до 3-5 лет. Ребенок осознает свое индивидуальное начало и самого себя как активно действующее существо. В это время у детей развивается чувство автономности или чувство зависимости от того, как взрослые реагируют на первые попытки ребенка добиться самостоятельности. На этом этапе развития самооценка тесно связана с чувством автономии. Ребенок более самостоятельный, более любознательный обычно обладает и более высокой самооценкой.

3 этап - от 5 до 7 лет. У ребенка появляются первые представления о том, каким он может стать человеком. В это время развивается либо чувство вины, либо чувство инициативы, в зависимости от того, насколько благополучно протекает процесс социализации ребенка, насколько строгие правила поведения ему предлагаются и насколько жестко взрослые контролируют их соблюдение. 
4 этап - школьные годы от 7 до 16 лет. Развитие чувства трудолюбия, способности к самовыражению в продуктивной работе. Опасность данного этапа: неумение выполнять определенные действия, низкий статус в ситуации совместной деятельности ведут $к$ появлению чувства собственной неадекватности. Ребенок может разувериться в своей способности участвовать в каком либо труде. Таким образом, развитие, происходящее в школьные годы, существенно влияет на представление человека о себе как о компетентном, творческом и способном работнике.

Становление самооценки в возрастном аспекте связано с овладением ребенком более совершенствованными способами самооценивания, с расширением, углублением знаний о себе, их обобщением и накоплением, наполнением их «личностными смыслами», с умением усилить их побудительно-мотивационную роль.

Некоторые факты о самооценке:

- дети очень рано начинают формировать представления о себе;

- дети ищут одобрения своих поступков у родителей и других взрослых людей;

- уровень самооценки имеет влияние на отношение к другим людям. Дети с положительным мнением о себе проще устанавливают дружеские взаимоотношения с окружающими;

- от самооценки зависит развитие творчества: дети с заниженной самооценкой редко обладают достаточной смелостью для активной творческой деятельности;

- в первую очередь на уровень самооценки ребенка влияют родители. Самооценка родителя отражается в том, как он воспитывает ребенка. Согласно исследованиям, дети с адекватной самооценкой вырастают и любящих и заботливых родителей. Низкая самооценка - признак критичности и излишней строгости родителей;

- дети с заниженной самооценкой чаще ссорятся с родителями и убегают из дома.

\section{Выявление самооценки и уровня притязаний детей дошкольного возраста}

Сведения о самооценке ребенка могут быть получены в процессе общения с ним, через наблюдения за поведением ребенка в разных жизненных ситуациях. В процессе наблюдения за поведением ребенка необходимо обращать внимание на следующие особенности, которые являются свидетельством низкого уровня самооценки и притязаний: 
1. Частые самокритичные высказывания: «Я не смогу этого сделать...»

2. Негативные ожидания в отношении ситуации соперничества: «Зачем это делать? У меня все равно будет хуже, чем у ...»

3. Критическое отношение к успехам других: «Просто ему повезло...»

4. Нежелание признавать свои ошибки: «Я не виноват, что...»

5. Склонность подчеркивать недостатки у других: «Зато он ябничает...»

6. Повышенная застенчивость, трудности общения с незнакомыми людьми.

7. Повышенная чувствительность к критике: «Все против меня»

8. Неспособность принять похвалу: «На самом - то деле вы так не считаете...»

9. Отказ от попыток добиться какого-то успеха: «Мне не интересно...» и т.Д.

А также, существуют разнообразные тесты, с помощью которых можно уточнить представления о самооценке и уровне притязаний ребенка. Я предлагаю рассмотреть некоторые из них:

1. Тест «Лесенка»;

Ребенку показывают нарисованную лесенку с семью ступеньками, где средняя ступенька имеет вид площадки, и объясняют задание.

Инструкиия: «Если всех детей рассадить на этой лесенке, то на трех верхних ступеньках окажутся хорошие дети: умные, добрые, сильные, послушные - чем выше, тем лучше (показывают: «хорошие», «очень хорошие», «самые хорошие»). А на трех нижних ступеньках окажутся плохие дети - чем ниже, тем хуже («плохие», «очень плохие», «самые плохие»). На средней ступеньке дети не плохие и не хорошие. Покажи, на какую ступеньку ты поставишь себя. Объясни почему?»

После ответа ребенка, его спрашивают: «Ты такой на самом деле или хотел бы быть таким? Пометь, какой ты на самом деле и каким хотел бы быть». «Покажи, на какую ступеньку тебя поставила бы мама».

Используется стандартный набор характеристик: «хороший - плохой», «добрый - злой», «умный - глупый», «сильный - слабый», «смелый трусливый», «самый старательный - самый небрежный». Количество характеристик можно сократить.

В процессе обследования необходимо учитывать, как ребенок выполняет задание: испытывает колебания, раздумывает, аргументирует свой 
выбор. Если ребенок не дает никаких объяснений, ему следует задать уточняющие вопросы: «Почему ты себя сюда поставил? Ты всегда такой?» и т.д.

Наиболее характерные особенности выполнения задания, свойственные детям с завышенной, адекватной и заниженной самооценкой.

Таблица 1

\section{Типы самооценки}

\begin{tabular}{|l|l|}
\hline \multicolumn{1}{|c|}{ Способ выполнения задания } & \multicolumn{1}{|c|}{ Тип самооценки } \\
\hline $\begin{array}{l}\text { 1. Не раздумывая, ставит себя на самую высокую ступеньку; } \\
\text { считает, что мама оценивает его также; аргументируя свой } \\
\text { выбор, ссылается на мнение взрослого: «Я хороший. Хороший и } \\
\text { больше никакой, это мама так сказала». }\end{array}$ & $\begin{array}{l}\text { Неадекватно } \\
\text { завышенная } \\
\text { самооценка }\end{array}$ \\
\hline $\begin{array}{l}\text { 2. После некоторых раздумий и колебаний ставит себя на самую } \\
\text { высокую ступеньку, объясняя свои действия, называет какие-то } \\
\text { свои недостатки и промахи, но объясняет их внешними, } \\
\text { независящими от него, причинами, считает, что оценка взрослых } \\
\text { в некоторых случаях может быть несколько ниже его } \\
\text { собственной: «Я, конечно, хороший, но иногда ленюсь. Мама } \\
\text { говорит, что я неаккуратный». }\end{array}$ & \\
\hline $\begin{array}{l}\text { 3. Обдумав задание, ставит себя на 2-ю или 3-ю ступеньку снизу, } \\
\text { объясняет свои действия, ссылаясь на реальные ситуации и } \\
\text { достижения, считает, что оценка взрослого такая же либо } \\
\text { несколько ниже. }\end{array}$ & $\begin{array}{l}\text { Адекватная } \\
\text { самооценка }\end{array}$ \\
\hline $\begin{array}{l}\text { 4. Ставит себя на нижние ступеньки, свой выбор не объясняет } \\
\text { либо ссылается на мнение взрослого: «Мама так сказала». }\end{array}$ & $\begin{array}{l}\text { Заниженная } \\
\text { самооценка }\end{array}$ \\
\hline
\end{tabular}

Если ребенок ставит себя на среднюю ступеньку, это может говорить о том, что он либо не понял задание, либо не хочет его выполнять. Дети с заниженной самооценкой из-за высокой тревожности и неуверенности в себе часто отказываются выполнять задание, на все вопросы отвечают: «Не знаю».

Дети с задержкой развития не понимают и не принимают это задание, действуют наобум.

Неадекватно завышенная самооценка свойственна детям младшего и среднего дошкольного возраста: они не видят своих ошибок, не могут правильно оценить себя, свои поступки и действия.

Самооценка детей 6-7-летнего возраста становится уже более реалистичной, в привычных ситуациях и привычных видах деятельности 
приближается к адекватной. В незнакомой ситуации и непривычных видах деятельности их самооценка завышенная.

Заниженная самооценка у детей дошкольного возраста рассматривается как отклонение в развитии личности.

2. Тест «Смешные человечки»

Покажите ребенку рисунок, на котором изображены смешные человечки, сидящие на дереве попросите показать, где располагается он, его друзья, родственники. Чем выше помещает себя ребенок на этом дереве, тем выше его самооценка. Чем выше он размещает остальных, тем лучше к ним относится, и тем большой значимостью они обладают в его глазах.

3. Тест «Почему не получается».

Необходимо предложить ребенку рассмотреть по очереди 4 картинки, на которых изображены его сверстники в ситуациях неуспеха в деятельности и попросите рассказать, что нарисовано, объяснить причину неудач детей, изображенных на картинках, и предложить свои варианты решения практической задачи.

На первой картинке (рис. а) изображено, как девочка берет лейку, хочет полить цветы, но не может ее поднять.

На второй картинке (рис. б ) нарисована скамейка, через которую прыгает мальчик, но видно, что он зацепился и падает.

На третьей картинке (рис. в) девочка собирается качаться на качелях, но никак не может на них забраться.

На четвертой картинке (рис. г) нарисован мальчик на склоне снежной горы со сломанной лыжей.

-Если, по мнению ребенка, причина неудач заключается в лейке, скамейке, качелях и горке, т. е. неудачи происходили по не зависящим от персонажей причинам, значит, он еще не научился оценивать себя и контролировать свои действия. Скорее всего, столкнувшись с неудачей, он бросит начатое дело и займется чем-нибудь другим.

-Если ребенок видит причину события в самих персонажах и предлагает им потренироваться, подрасти, набраться сил, позвать на помощь, значит, у него высокая самооценка и самоконтроль поведения.

- О развитой способности к всестороннему анализу ситуации можно говорить и тогда, когда ребенок видит причину неудач и в персонажах, и в объектах.

Второй и третий варианты свойственны детям, которые достаточно адекватно оценивают себя и контролируют свою деятельность. 
4. Тест на определение самооценки и уровня притязаний «Какой я».

Проведите с ребенком беседу с целью выяснения его отношения к привлекательным и непривлекательным качествам человека и отношения к себе, например:

- Представь себе человека, который бы тебе так нравился, что ты хотел бы быть таким, как он, хотел бы быть похожим на него. Какой это человек? Каким быты хотел быть? На кого бы ты хотел быть похожим?

- Представь себе человека, который бы тебе настолько не нравился, что ты ни за что не хотел бы быть таким, как он, не хотел бы быть похожим на него. Какой это человек? Каким бы ты не хотел быть? На кого бы ты не хотел быть похожим?

- Что ты можешь рассказать о себе? Какой ты сам?

Ребенку предъявляют шкалу с характеристиками названными детьми в ответах на вопросы и стандартный набор антонимов ("хороший - плохой", "добрый - злой", "умный - глупый", "смелый - трусливый", "сильный слабый" и т.д.)

Экспериментатор дает следующую инструкцию: "На этой шкале - все люди на свете: от самых добрых до самых злых (показ сопровождается движением руки по шкале сверху вниз), от самых злых до самых добрых (движение руки снизу вверх по шкале) На самом верху находятся все самые добрые люди на свете, в самом низу - самые злые, посередине - средние. Где ты среди всех этих людей? Отметь свое место фишкой". После того как ребенок сделал выбор, его спрашивают: "Ты такой на самом деле или хотел бы быть таким? Отметь, какой ты на самом деле и каким бы хотел быть".

Идеальная и реальная самооценки производятся по различным индивидуально-психологическим качествам несколько раз.

По итогам беседы выявляют наличие и характер представлений ребенка о себе, его ценностные суждения и пристрастия.

По результатам, полученным во второй серии эксперимента сравнивают, сколько детей обладает максимально высокой самооценкой, сколько дифференцированной (различение оценок в идеальном и реальном плане) в начале и конце учебного года.

Мы можем узнать о наличии и характере представлений ребенка о себе, ознакомиться с его ценностными суждениями, понять, какой у него уровень самооценки и уровень притязаний. 


\section{Рекомендации по формированию адекватной самооценки детей дошкольного возраста}

Следует уделять большое внимание развитию адекватной самооценки у детей дошкольного возраста, это можно делать различными средствами:

- поощрять ребенка за положительные поступки;

- не говорить ребенку, что он хуже других или такой же как все;

- постоянно развивать в ребенке индивидуальность, чувство компетентности;

- давать адекватную оценку его поступкам;

-предоставлять ребенку самостоятельность;

-не требовать от ребенка невозможного

-воспитывать уверенность.

Соблюдение вышеперечисленных рекомендаций в воспитании детей обеспечит наиболее благоприятное развитие детской психики, а также формирование адекватной самооценки и уровня притязаний.

Для формирования у ребенка положительного осознания себя, уверенности в себе необходимо обеспечить малышу теплое отношение взрослых. Ребенку просто необходимо ощущать себя любимым, единственным. Ему нужно знать, быть уверенным, что его, именно таким, какой он есть, любят родители и воспитатели. И только тогда в дошкольнике появится уверенность, положительное отношение к себе, будет формироваться адекватная самооценка, и он будет развиваться как полноценная, гармоничная личность.

Формирование адекватного уровня притязаний лучше всего со старшими дошкольниками реализовать в игровой деятельности. Мы знаем, что дети, обладающие завышенной самооценкой, отличаются некритичным отношением к себе, они стремятся не замечать неудач, игнорируют замечания взрослых, неадекватно реагируют на оценки. А в отношении к своим сверстникам, напротив, очень критичны, им свойственно обсмеять товарища за малейший промах, указать на недостатки.

В таких случаях очень эффективно использовать детские игры с карточками-фиксаторами. Использование карточек позволит ребенку наглядно убедиться в результатах собственной деятельности, а не игнорировать их. В ходе игры используется прием «самокритичный взрослый», когда взрослый на своем примере демонстрирует ребенку правильное отношение к неудачам и успеху, учит ребенка не бояться признать 
поражение и показывает взаимосвязь между стараниями и результатом. Такая позиция взрослого позволяет стать истинным партнером ребенку.

Первоначально взрослый должен в 50\% случаев давать выиграть дошкольнику. Взрослый может сказать: «Ты выиграл. А мне надо еще потренироваться». В этом случае ребенок видит, что неудовлетворительный результат воспринимается как мотивация для дальнейших усилий для достижения успеха. Постепенно ребенок начинает сам осознавать свои неудачи как повод для поиска более точных движений. Так формируется самокритичность, ребенок начинает прислушиваться к советам, оценкам и адекватно реагировать на них.

Затем взрослый может выигрывать чаще, и ребенок уже не будет стремиться игнорировать свой проигрыш. Нужно помочь ребенку подсчитать карточки, осознать, что этот раз он не победил, и в этом нет ничего трагичного или постыдного. Значит, в следующий раз нужно приложить больше старания, потренироваться. Когда ребенок уже адекватно реагирует на свои поражения, понимает, что, чем больше он старается, тем лучше у него получится, тогда повышается продуктивность и эффективность деятельности. Формируются такие черты характера, как целеустремленность, стремление к самосовершенствованию. Дети начинают самостоятельно выбирать для себя новые цели, усложнять задачи. Такие черты характера присущи детям с адекватной самооценкой.

В коррекции нуждаются и дошкольники с заниженным уровнем притязаний. Известно, что они страдают не меньше, а даже больше, чем дети с завышенным уровнем притязаний. Дети с низкой самооценкой отличаются неуверенностью в себе, стеснительностью, робостью. Они не решительны, не самостоятельны.

Чтобы помочь такому ребенку, взрослый должен действовать очень осторожно, чтобы не травмировать его. Для начала взрослый (педагог), понаблюдав за ребенком, может заняться с ребенком его любимым делом. За малейшие достижения ребенка нужно хвалить, акцентировать внимание на его успехе. Нужно дать дошкольнику пережить ситуацию успеха, победы, которой, быть может, он лишен в детском коллективе. В игре взрослый может проигрывать. Говоря ребенку, что он выиграл (можно использовать карточки, для того, чтобы ребенок самостоятельно убедился в победе), необходимо отметить, почему это удалось ему. Это поможет ребенку увидеть причинноследственную связь: он выиграл не потому, что он хороший, а потому что он 
приложил старания, усилия и т.п. Когда ребенок добивается успеха, необходимо обратить на это внимание других детей, привлечь их к положительной оценке: «Дети, вам нравится рисунок? Красивый, видно, что ты старался!» и т.п.

Для повышения статусного положения дошкольника с низким уровнем притязаний необходимо постоянно включать ребенка в игровую деятельность, чаще давать ему поручения (как правило, такие дети очень исполнительны), постепенно давать им главные роли в спектаклях, сценках.

Таким образом, у дошкольника появится уверенность в себе, своих способностях, он станет более смелым, решительным, общительным. Дети в группе станут по-другому относиться к нему, будут приглашать играть вместе. А это поддержит уверенность дошкольника в себе, сделает его более активным, инициативным. Но важна гармоничность, согласованность действий родителей и воспитателей. Совершенно недопустимо, чтобы в детском саду педагоги стремились повысить самооценку ребенка, а дома родители или старшие братья и сестры, в силу своей некомпетентности сводили эти усилия к нулю.

Ценность личности измеряется в большей мере тем, что, как и для чего человек умеет делать. Правильное осознание своих умений, действий является не только средством и условием успешного обучения, но имеет также большое воспитательное значение как фактор формирования лучших качеств личности. Дошкольник, становится самостоятельным, более независимым от взрослых. Его взаимоотношения с окружающими расширяются и усложняются. Это дает возможность более полно и глубоко осознать себя и оценить.

Вся психическая жизнь ребенка развивается под воздействием оценок окружающих; каждый новый опыт, новое знание, умение, приобретенное ребенком, оценивается окружающими. И скоро ребенок сам начинает искать оценку своих действий, подкрепление правильности или неправильности познаваемой им действительности.

Знать оценочные и самооценочные действия дошкольника очень важно для установления отношений с ним, для нормального общения, в которое ребёнок включаются. С возрастом ребенок все с большей определенностью различает свои действительные достижения и то, чего он мог бы достичь, обладая определенными личностными качествами. 
В самооценке отражается то, что ребенок узнает о себе от других, и его возрастающая собственная активность, направленная на осознание своих действий и личностных качеств. Как и все другие особенности личности, его самооценка складывается в процессе воспитания, в котором основная роль принадлежит семье и детскому саду. Кроме осознания своих качеств дошкольники пытаются осмыслить мотивы своих и чужих поступков, начинают объяснять собственное поведение, опираясь на знания и представления, почерпнутые от взрослого, и собственный опыт.

\section{Список литературы}

1. Абрамова Г.С. Практикум по возрастной психологии: Учеб. пособие для студентов вузов. - 2-е изд., стереотип. - М., 2009. - 320 с.

2. Аверин В.А. Психология детей и подростков. СПб., 2008г. -279 с.

3. Баланда Е.Я - это все мои "Я" (о самооценке) // Психологический журнал 2010. - 4., с. 12-15.

4. Валлон А. Психическое развитие ребенка. - СПб., 2011. - 208 с.

5. Выготский Л.С. Вопросы детской психологии. - СПб., 2010. - 323 с.

6. Детская практическая психология: Учебник для студентов вузов/Под ред. Т.Д. Марцинковской. - М., 2011. - 247 с

7. Ильина М.Н. Подготовка к школе: развивающие тесты и упражнения. - СПб.: Питер,2004.-205 с.:ил.

8. Коротенко И.В. Как формировать самооценку дошкольника. М. 2012.

9. Рогов Е.И. Настольная книга практического психолога. В 2 кн.- М.: Изд-во ВЛАДОС-ПРЕСС, 2006.

10. Чащин Л.В. Что такое самооценка?// Психологический журнал . 2012год. 